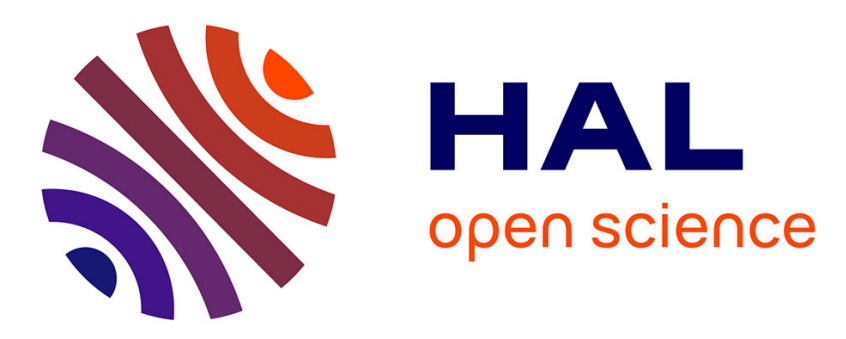

\title{
Failure design of high-rise concrete panels under fire loading
}

Jeremy Bleyer, Duc Toan Pham, Patrick de Buhan

\section{To cite this version:}

Jeremy Bleyer, Duc Toan Pham, Patrick de Buhan. Failure design of high-rise concrete panels under fire loading. Proceedings of the ICE - Engineering and Computational Mechanics, 2015, Themed issue on direct methods - part two, 168 (4), pp.178-185. 10.1680/eacm.14.00028 . hal-01283598

\section{HAL Id: hal-01283598 \\ https://hal.science/hal-01283598}

Submitted on 5 Mar 2016

HAL is a multi-disciplinary open access archive for the deposit and dissemination of scientific research documents, whether they are published or not. The documents may come from teaching and research institutions in France or abroad, or from public or private research centers.
L'archive ouverte pluridisciplinaire HAL, est destinée au dépôt et à la diffusion de documents scientifiques de niveau recherche, publiés ou non, émanant des établissements d'enseignement et de recherche français ou étrangers, des laboratoires publics ou privés. 


\title{
Failure design of high rise concrete panels under fire conditions
}

\author{
J. BLEYER ${ }^{*} \ddagger$, D.T. PHAM $^{*} \dagger$ and P. DE BUHAN*
}

\begin{abstract}
The present contribution addresses the crucial issue of predicting the failure of high rise reinforced concrete walls subjected to fire loading conditions. A three step procedure is proposed, in which the yield design (limit analysis) method is applied on two separate levels. First, as a way for assessing the local strength properties of the wall, modeled as a plate, as a function of temperature gradient across the wall thickness. Secondly for analyzing the overall stability of the wall in its fire-induced deformed configuration on account of the previously determined strength properties. A comprehensive numerical approach is set up, based on fem-based plate yield design computations associated with non-linear optimization schemes, and a first illustrative application is performed leading to first conclusive results regarding structural fire safety.
\end{abstract}

KEYWORDS: high rise walls; structural fire safety; yield design; periodic plates and shells; finite elements; non-linear optimization.

ICE Publishing: all rights reserved

\section{INTRODUCTION}

Evaluating the ultimate load bearing performance of reinforced concrete members under fire exposure has gained increasing attention in the last decades (see among many others Lie \& Celikkol (1991); Franssen \& Dotreppe (2003); El-Fitiany \& Youssef (2009)). Attention has been more particularly focused on the determination of axial force-bending moment interaction diagrams of a reinforced concrete section subjected to a fire induced temperature gradient (Caldas et al. (2010); Law \& Gillie (2010)). In this context, the yield design (or limit analysis) approach (Chen (1982); Salençon (2013)) has proved being a suitable framework for determining such interaction diagrams in a rigorous way, either under ambient temperature (Averbuch (1996); Koechlin \& Potapov (2007)), or when subjected to a fire-induced temperature gradient (Pham et al. (2015a)).

High rise concrete walls are large size reinforced concrete structures for which the analysis of fire resistance requires a more sophisticated approach than for conventional, i.e. smaller size structures. The sole degradation of the stiffness and strength properties of reinforced concrete due to severe temperature increase, cannot explain as such the collapse of these structures. The purpose of the present contribution is to

\footnotetext{
Manuscript received...

Published online at www.ECM.com

* Université Paris-Est, Laboratoire Navier (Ecole des Ponts ParisTech, IFSTTAR, CNRS UMR 8205), 6-8 avenue Blaise Pascal, Cité Descartes, Champs-sur-Marne, 77455 Marne-laVallée Cedex 2, France

†Université Paris-Est, Centre Scientifique et Technique du Bâtiment (CSTB), 84 avenue Jean Jaurès, Champs-sur-Marne, 77447 Marne-la-Vallée Cedex 2, France.

†Corresponding author: jeremy.bleyer@enpc.fr
}

extend the range of application of the yield design approach (Salençon (2013)) in order to analyse the global stability of high rise walls, taking the geometry changes induced by the thermal loading into account, in addition to the fire-induced decay of material stiffness and strength properties. The main original feature of the present approach lies therefore in the fact that the geometric configuration of the high rise wall on which the yield design approach is to be performed, is not known a priori, but should be determined from a preliminary calculation accounting for geometrically non-linear second order effects.

The whole procedure has already been applied in the particular case when the high rise wall can be modelled as a one dimensional beam-column (Pham et al. (2015b)). It is here extended to rectangular reinforced concrete panels, which can be adequately schematized as a two-dimensional plate (slab) or shell of low curvature in its deformed configuration. An illustrative application of the whole design procedure will be presented, pointing, as a first conclusion, to the very high sensitivity of the wall failure with respect to its width.

\section{OUTLINE OF A THREE-STEP PROCEDURE}

Due to the thermal deformations induced by the fire exposure on one of its face, high rise panels exhibit potentially important out-of-plane (horizontal) displacements, which lead to an eccentricity of the gravity load (self-weight) with respect to the initial plane (Figure 1). As a consequence, bending moments are generated in the wall in addition to the preexisting compressive membrane forces distribution, which is usually known as a second order (or P-delta) effect (see for instance the classical textbook by Bazant \& Cedolin (2010)). As the eccentricity increases, the moment due to 

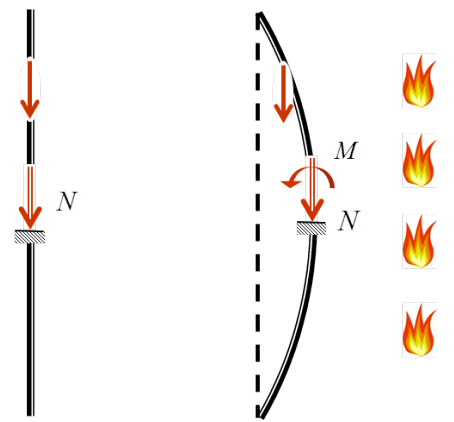

Fig. 1. Schematic view of a high rise wall subject to fire loading: (left) initial and (right) deformed configurations

self-weight eccentricity also increases, thus subjecting the wall to still higher bending moments and associated curvature deformations. Simultaneously, but independently, elevated temperature leads to degrading the mechanical properties of constituent materials. It is the combined effect of fire-induced material strength degradation and development of bending moments due to geometry change, which may trigger an overall failure of the structure, even before the occurrence of any buckling phenomenon.

Following such a line of reasoning, this contribution will implement a three-step computational procedure, summarized in the flowchart of Figure 2 below.

- Step $n^{\circ}$ 1. Preliminary determination of the wall deformed configuration. This step consists in evaluating the equilibrium configuration of the wall under the combined action of thermal gradient (due to a temperature increase of one of the wall face from $20 \mathrm{C}$ to $1050 \mathrm{C}$ ) and self-weight, through the use of a classical fem-based thermo-elastic computational tool accommodating for second order effects.

- Step $n^{\circ}$ 2. Determination of temperature dependent interaction diagrams. The objective of this phase, which is completely independent from the first one, is to determine the membrane forces-bending moments yield strength capacities of any wall cross-section as a function of the prescribed temperature gradient, as it has been done for heterogeneous periodic plates (Bleyer \& de Buhan (2014)).

- Step $n^{\circ}$ 3. Yield analysis and design of the wall in its deformed configuration determined in step $\mathrm{n}^{\circ} 1$, on account of its reduced strength properties evaluated in step $n^{\circ} 2$. This will be performed by means of a finite element formulation of the yield design plate (or more precisely shallow shell) problem (Bleyer \& de Buhan (2013)), making use of the yield design static and kinematic approaches, thereby leading to the formulation of a non linear optimization problem.

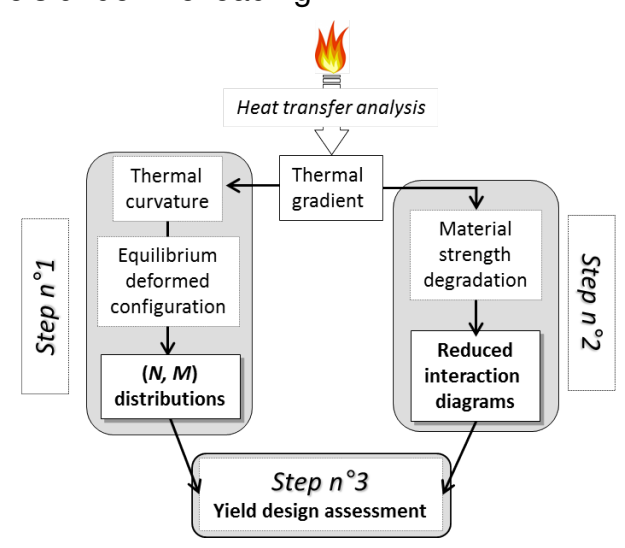

Fig. 2. A three-step evaluation procedure for the yield design of fire loaded high rise vertical walls

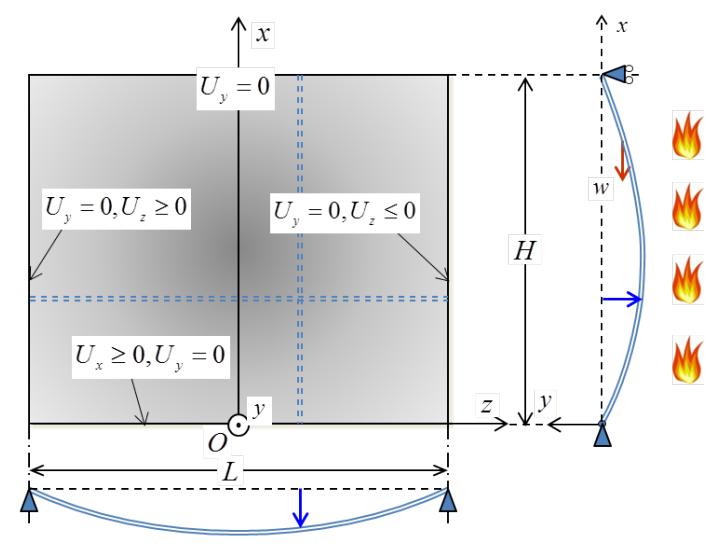

Fig. 3. Geometrical characteristics and prescribed boundary conditions for the vertical panel regarded as a simply supported plate.

One of the important differences with the case where the panel is modelled as a one-dimensional beam (see Pham et al. (2015b)), is that steps 2 and 3 will not be treated separately but simultaneously within the same global optimization procedure.

\section{PREDICTING THE THERMAL-INDUCED EQUILIBRIUM CONFIGURATION OF THE PANEL}

Prior to the application of thermal loading, the panel is modelled as a plane rectangular vertical plate of height $H$ and width $L$ contained in the $O x z$-plane as shown in Figure 3 , where the different boundary conditions corresponding to situations encountered in practice, are specified. In short, the plate is simply supported along its four edges (free rotation along these edges), while the other prescribed kinematic conditions indicate that the panel is free to move both horizontally and vertically along its upper edge, horizontally and vertically upwards along the lower edge, and vertically and horizontally to the right (resp. to the left) along the left (resp. right) hand lateral side.

The wall being subjected to its own weight only, characterized by a uniform in-plane surface vertical density $w$, the thermal loading is applied by progressively increasing 


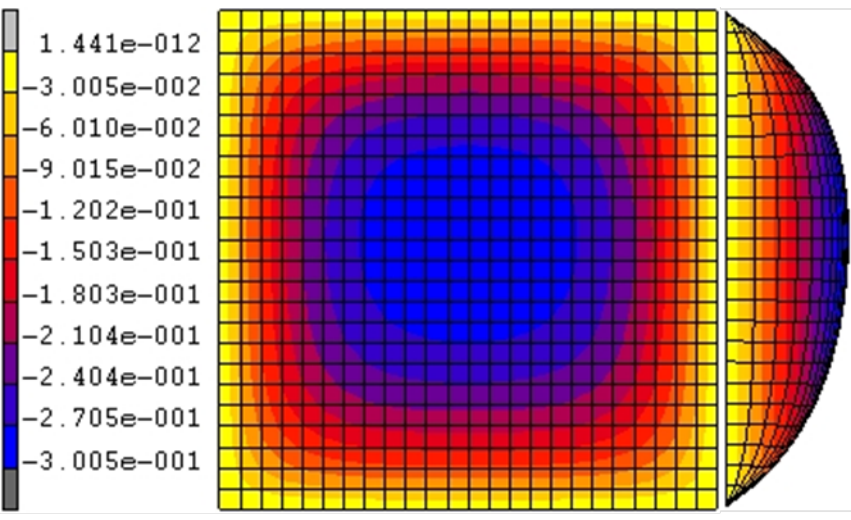

Fig. 4. Contours of the panel out-of-plane displacements for $L=12 \mathrm{~m}$ : face and side views.

the temperature on one face. The problem is then analysed by means of the MARC finite element code (MSC (2007)) in the context of a thermo-elastic behaviour, with two specific features (see Pham et al. (2015b) for a detailed presentation).

a) Thermo-elastic strains as well as rotations remain small, but the change of geometry produced by horizontal out-of-plane displacements is taken into account in an explicit way, through the emergence of bending moment distributions and related elastic bending curvatures due to self weight eccentricity.

b) The influence of high temperature on the material stiffness degradation is accounted for through experimentally derived curves, giving for instance the variation of the concrete Youngs modulus as a function of temperature (EN1992-1-2 (2004)).

The finite element simulation has been carried out with the following sets of data:

$$
\begin{gathered}
L=12 \mathrm{~m} \text { and } L=60 \mathrm{~m}, H=12 \mathrm{~m}, h=0.15 \mathrm{~m}, \\
w=3.68 \mathrm{kN} / \mathrm{m}^{2}, E_{c}=19.2 \mathrm{GPa}, \Theta_{\max }=1050{ }^{\circ} \mathrm{C}
\end{gathered}
$$

where $h$ is the wall thickness and $E_{c}$ the concrete Youngs modulus at ambient temperature, one of the walls face being subjected to an ISO 834 fire (EN1991-1-2 (2002)).

The result of the non-linear finite element simulation for $L=12 \mathrm{~m}$ is represented in Figure 4, in the form of the contours of the out-of-plane displacements experienced by the wall for a $120 \mathrm{mn}$ fire exposure (values in meters). The displacement profile of the side view has been magnified by a factor 10 . As expected, the displacement reaches its maximum value of $0.30 \mathrm{~m}$ in the central part of the panel.

\section{TEMPERATURE DEPENDENT YIELD STRENGTH CAPACITIES OF THE PANEL}

Following the same kind of upscaling procedure as that adopted for determining the interaction diagram of a reinforced
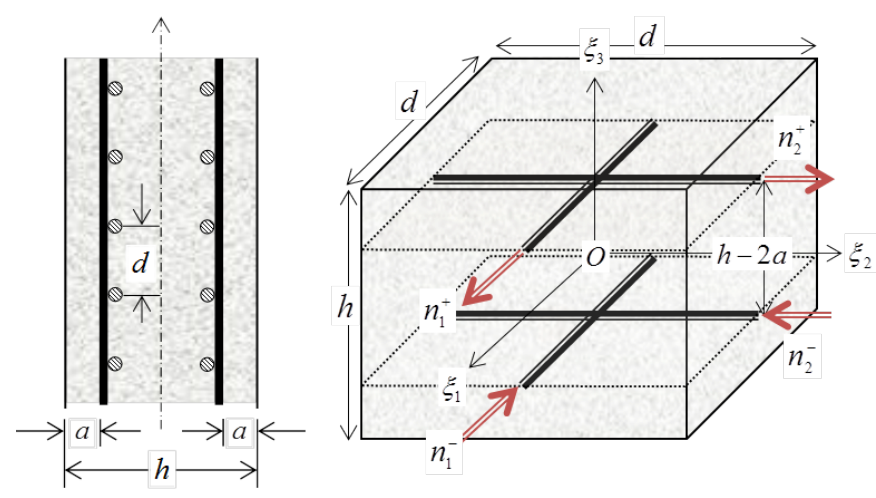

Fig. 5. Yield design auxiliary problem for determining the reinforced concrete panel strength capacities

concrete beam (Pham et al. (2015b)), the strength capacities of the reinforced concrete panel, formulated as a condition involving the membrane forces and bending moments, can be determined from solving a yield design auxiliary problem defined as follows. A representative volume of the reinforced concrete panel is shown in Figure 5, in the form of a rectangular parallelepiped of height $h$ equal to the wall thickness, and side $d$ equal to the spacing between to reinforcing bars. The latter are organized in four arrays placed along the two orthogonal directions of unit vectors $\underline{e}_{1}$ and $\underline{e}_{2}$ at a distance $a$ from the upper and lower surfaces.

Referring to the lower bound static approach of yield design for this particular problem, plane stress fields of the form:

$$
\underline{\underline{\sigma}}=\sigma_{\alpha \beta}\left(\xi_{3}\right) \underline{e}_{\alpha} \otimes \underline{e}_{\beta} \quad \alpha, \beta=1,2
$$

are considered in the concrete material, while each of the four reinforcing bars, modelled as 1D structural elements embedded in the concrete material, undergoes a purely axial force denoted by $n_{\alpha, \beta}^{ \pm}$(see Figure 5).

The concrete material obeys a Mohr-Coulomb tension cutoff strength condition which can be written as:

$$
F\left(\sigma_{\alpha \beta}\right) \leq 0 \Leftrightarrow\left\{\begin{array}{l}
-2 f_{c} \leq \sigma_{11}+\sigma_{22} \leq 0 \\
\sigma_{11} \sigma_{22}-\sigma_{12}^{2} \leq 0 \\
\left(\sigma_{11}+f_{c}\right)\left(\sigma_{22}+f_{c}\right)-\sigma_{12}^{2} \leq 0
\end{array}\right.
$$

where $f_{c}$ is the uniaxial compressive strength of the concrete material, while each reinforcement obeys the following strength condition:

$$
\left|n_{\alpha, \beta}^{ \pm}\right| \leq A f_{y}
$$

where $f_{y}$ is the reinforcing material (steel) uniaxial yield strength and $A=\pi \phi^{2} / 4$ the cross sectional area of each individual bar of diameter $\phi$.

Under such conditions, it can be proved that the panel strength criterion expressed in terms of in plane membrane forces and 


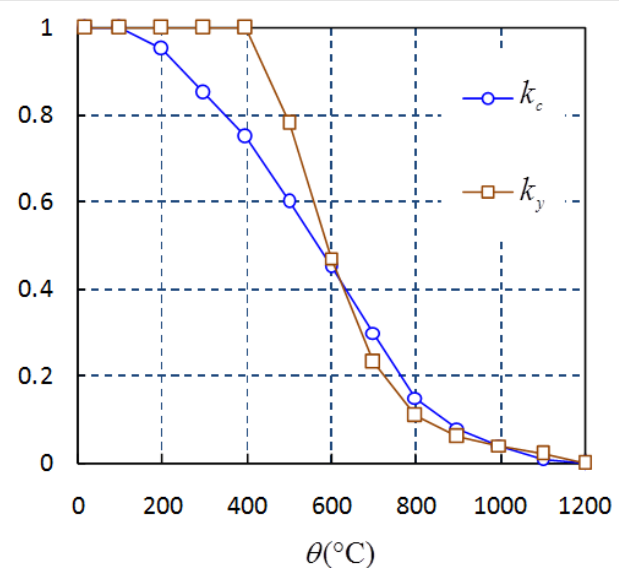

Fig. 6. Evolution of concrete and reinforcement strength reduction factors with temperature increase (EN1992-1-2 (2004))

bending moments, is defined as:

$$
F^{h o m}\left(N_{\alpha \beta}, M_{\alpha \beta}\right) \leq 0 \Leftrightarrow
$$

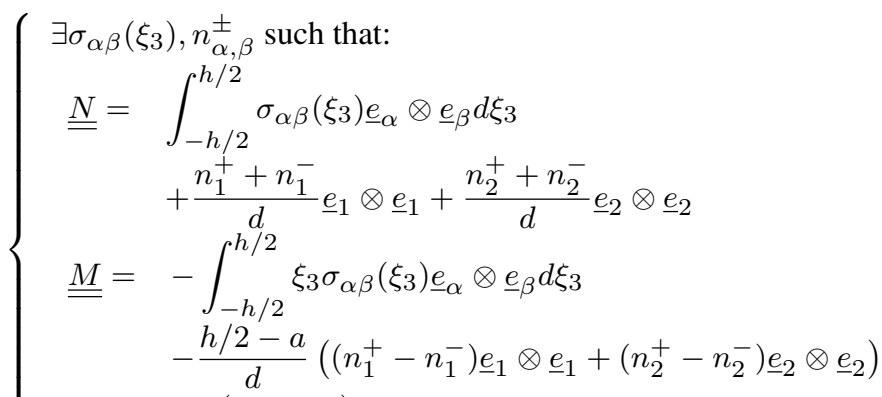

subject to $F\left(\sigma_{\alpha \beta}\left(\xi_{3}\right)\right) \leq 0 \forall \xi_{3} \in[-h / 2 ; h / 2]$

and $\quad\left|n_{\alpha, \beta}^{ \pm}\right| \leq A f_{y}$

When a thermal loading is applied, characterized by a temperature increase profile $\theta\left(\xi_{3}\right)$ across the wall thickness, the material yield strength properties are modified through the introduction of non dimensional reduction coefficients, the variation of which with temperature, is shown in Figure 6:

$$
f_{c}\left(\xi_{3}\right)=k_{c}\left(\theta\left(\xi_{3}\right)\right) f_{c} \quad \text { and } \quad f_{y}\left(\xi_{3}\right)=k_{y}\left(\theta\left(\xi_{3}\right)\right) f_{y}
$$

The numerical yield design calculations presented in the next section have been performed with the following geometrical characteristics and strength properties at ambient temperature $\left(\theta=20^{\circ} \mathrm{C}\right)$ :

$d=10 \mathrm{~cm}, a=3 \mathrm{~cm}, \phi=6 \mathrm{~mm}, f_{y}=500 \mathrm{MPa}, f_{c}=32 \mathrm{MPa}$

\section{STABILITY ANALYSIS OF THE PANEL IN ITS DEFORMED CONFIGURATION: A FINITE ELEMENT APPROACH}

The stability analysis of the wall is assessed using finite element-based yield design static and kinematic approaches in the deformed configuration by estimating a safety factor $\lambda^{+}$ corresponding to the non-dimensional multiplicative factor of the loading at which the wall collapses in the sense of yield design. The wall is discretized as an assembly of triangular facets and each triangular finite element is a combination of a plate bending and a membrane finite element.

\section{Implementation of the static approach}

In each finite element, a linear interpolation of the in-plane membrane tensor $\underline{\underline{N}}$ and a quadratic interpolation of the bending moment tensore $\underline{\underline{M}}$ are considered, these fields being a priori discontinuous from one element to another.

The local equilibrium inside each facet, the continuity conditions between two adjacent facets and the boundary conditions can be written as a global linear equality of the form $\mathbf{H} \boldsymbol{\Sigma}+\mathbf{F}=\mathbf{0}$ where $\boldsymbol{\Sigma}=\left\{N_{\alpha \beta}^{e}, M_{\alpha \beta}^{e}, V_{\alpha}^{e}\right\}^{T}$ is the generalized vector of static unknowns and $\mathbf{F}$ the global vector of external loads (weight).

The panel strength criterion (5) cannot be written as such in practice. A lower bound approximation $F_{i n t}^{n}\left(N_{\alpha \beta}, M_{\alpha \beta}\right) \leq 0$ is thus obtained by considering piecewise constant stress fields $\sigma_{\alpha \beta}$ in $n$ different layers of the wall thickness. This implicit discretization also enables to account for the evolution of the concrete strength in the wall thickness.

Finally, for a given discretization, a lower bound estimate $\lambda_{l b}$ of the safety factor $\lambda^{+}$can be obtained by solving the following non-linear convex optimization problem:

$$
\begin{aligned}
\lambda^{+} \geq \lambda_{l b}=\max _{\boldsymbol{\Sigma}} & \lambda \\
\text { s.t. } & \mathbf{H} \boldsymbol{\Sigma}+\lambda \mathbf{F}=\mathbf{0} \\
& F_{i n t}^{n}\left(N_{\alpha \beta}^{e}, M_{\alpha \beta}^{e}\right) \leq 0 \quad \forall e
\end{aligned}
$$

Due to the particular form of the tension cut-off MohrCoulomb criterion in plane stress (3), the non-linear constraints $F_{i n t}^{n}\left(N_{\alpha \beta}^{e}, M_{\alpha \beta}^{e}\right) \leq 0$ can be expressed as a combination of linear constraints and second-order conic (SOC) constraints, so that the previous optimization problem can be formulated as a second-order cone programming (SOCP) problem for which very efficient interior-point solvers, like the MOSEK software package Mosek (2002), are available.

\section{Implementation of the kinematic approach}

The kinematic approach is based upon the consideration of a virtual shell kinematics consisting of a virtual velocity field $\underline{u}$ and an angular velocity field $\underline{\theta}$ which are linked in each facet by a Love-Kirchhoff kinematic constraint, due to the fact that the shear resistance of the wall is assumed to be infinite. The stability of the wall in the sense of the yield design kinematic approach is then assured if :

$$
\begin{gathered}
\forall(\underline{u}, \underline{\theta}) \text { kinematically admissible } \\
W_{\text {ext }}(\underline{u}, \underline{\theta}) \leq W_{r m}(\underline{u}, \underline{\theta})=\int_{\Omega} \pi^{h o m}(\underline{\underline{\delta}}, \underline{\underline{\chi}}) d \Omega
\end{gathered}
$$


where $W_{\text {ext }}$ denotes the work of external loads, $W_{r m}$ denotes the maximum resisting work computed using the wall strength criterion support function defined as :

$$
\pi^{h o m}(\underline{\underline{\delta}}, \underline{\underline{\chi}})=\sup _{F^{h o m}(\underline{\underline{N}}, \underline{\underline{M}}) \leq 0}\{\underline{\underline{N}}: \underline{\underline{\delta}}+\underline{\underline{M}}: \underline{\underline{\chi}}\}
$$

$\underline{\underline{\delta}}$ being the in-plane membrane strain tensor and $\underline{\underline{\chi}}$ the bending curvature strain associated to the virtual velocity $\overline{\bar{f}}$ ields.

A quadratic interpolation for $\underline{u}$ and a linear interpolation for $\underline{\theta}$ are considered in each finite element, these fields being a priori discontinuous from one element to another, the contribution of the potential discontinuities ("yield lines") being taken into account when computing the maximum resisting work. The strain-velocity compatibility conditions are written as $\boldsymbol{\delta}=\left\{\delta_{\alpha \beta}^{e}\right\}=\mathbf{B}_{\delta} \mathbf{U}$ et $\boldsymbol{\chi}=\left\{\chi_{\alpha \beta}^{e}\right\}=\mathbf{B}_{\chi} \mathbf{U}$ where $\mathbf{U}$ denotes all kinematic unknowns. The work of external loads is then given by $W_{e x t}=\mathbf{F}^{T}$. U. Finally, the maximum resisting work is approximated by a numerical integration quadrature in each triangle and on each edge of the mesh.

Due to the specific form of the strength criterion (5), it can be shown that its support function is given by the sum of the concrete contribution and the reinforcing bars contribution:

$$
\begin{aligned}
\pi^{h o m}(\underline{\underline{\delta}}, \underline{\underline{\chi}})= & \int_{-h / 2}^{h / 2} \Pi\left(\underline{\underline{\delta}}-\xi_{3} \underline{\underline{\chi}} ; \xi_{3}\right) d \xi_{3} \\
& +N_{y}(a)\left(\left|\delta_{11}-a \chi_{11}\right|+\left|\delta_{22}-a \chi_{22}\right|\right) \\
& +N_{y}(-a)\left(\left|\delta_{11}+a \chi_{11}\right|+\left|\delta_{22}+a \chi_{22}\right|\right)
\end{aligned}
$$

where $N_{y}\left(\xi_{3}\right)=\frac{A}{d} f_{y}\left(\xi_{3}\right), \Pi\left(\underline{\underline{d}} ; \xi_{3}\right)=\sup _{F\left(\sigma_{\alpha \beta}\right) \leq 0}\{\underline{\underline{\sigma}}: \underline{\underline{d}}\}$ is the support function of the Mohr-Coulomb strength criterion at $\xi_{3}$. In practice, the remaining integral is estimated by excess using a $n$-points trapezoidal quadrature rule.

Finally, an upper bound estimate $\lambda_{u b}$ of the safety factor is obtained by solving the following non-linear convex optimization problem:

$$
\begin{aligned}
\lambda^{+} \leq \lambda_{u b}=\min _{\mathbf{U}} & \sum_{e}\left(\sum_{i=1}^{n} \omega_{e, i} \Pi\left(\mathbf{d}_{i} ; \xi_{3}^{i}\right)+\sum_{k=1}^{4} N_{y}^{k}\left|d_{a}^{k}\right|\right) \\
\text { s.t. } \quad \mathbf{F}^{T} \cdot \mathbf{U}=1 & \mathbf{d}_{i}=\boldsymbol{\delta}-\xi_{3}^{i} \chi=\left(\mathbf{B}_{\delta}-\xi_{3}^{i} \mathbf{B}_{\chi}\right) \mathbf{U} \quad \forall i \\
& d_{a}^{1}=\delta_{11}-a \chi_{11}, d_{a}^{2}=\delta_{22}-a \chi_{22} \\
& d_{a}^{3}=\delta_{11}+a \chi_{11}, d_{a}^{4}=\delta_{22}+a \chi_{22}
\end{aligned}
$$

where $\omega_{e, i}$ are integration weights and $\xi_{3}^{i}$ are integration points in the thickness direction (note that the discontinuity term has not been written for the sake of concision).

Again, due to the particular form of the Mohr-Coulomb criterion, its support function can be expressed using secondorder cone constraints, so that the previous problem is a SOCP problem as well and can be solved using the same solver.

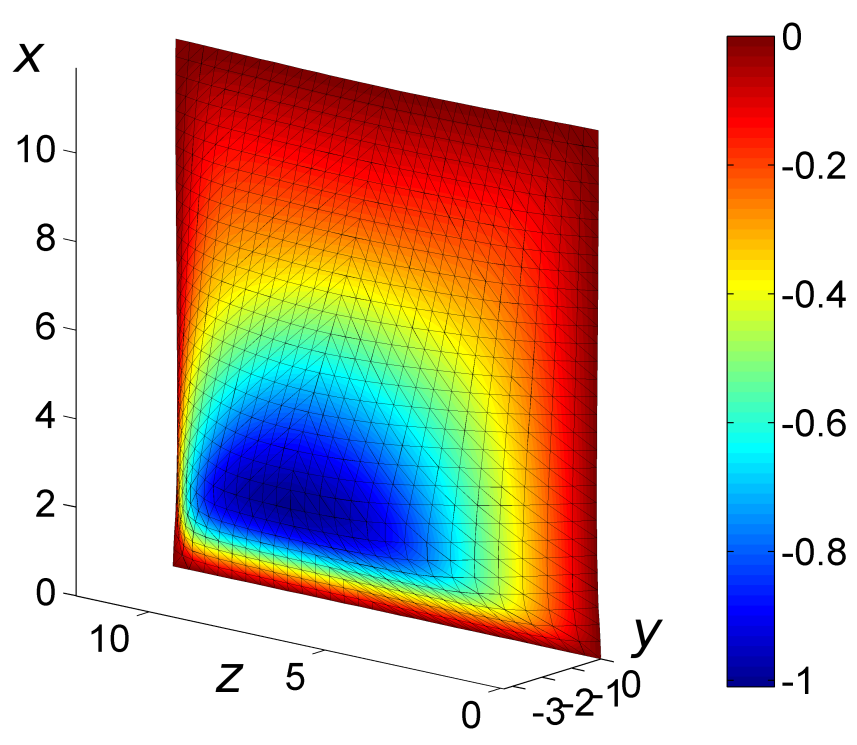

Fig. 7. Optimal failure mechanism obtained in the kinematic approach for $L=12 \mathrm{~m}$ (contours represent the relative amplitude of the $U_{y}$ velocity)

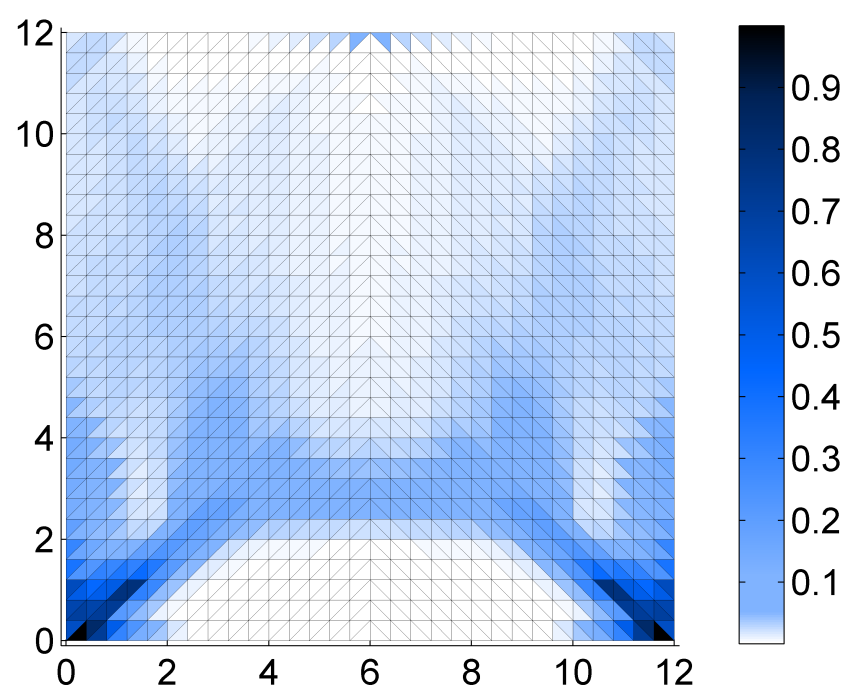

Fig. 8. Relative distribution of the support function $\pi^{h o m}(\underline{\underline{\delta}}, \underline{\underline{\chi}})$ for $L=12 \mathrm{~m}$ : face view

\section{RESULTS AND COMMENTS}

The finite element computations have been performed on a half wall (with appropriate symmetry conditions) discretized into 900 triangular finite elements and using $n=10$ integration points for the strength criterion and support function computation. The optimization problems have been solved by MOSEK in a few minutes only.

The values of the computed safety factor estimates have been reported in Table 1 for the considered geometry. One can observe that the relative gap between the lower bound static approach and the upper bound kinematic approach is of $12 \%$ which can be considered as a quite good estimation 


\begin{tabular}{|c|c|c|c|}
\hline Geometry & $\lambda_{l b}$ & $\lambda_{u b}$ & Relative gap \\
\hline $12 \mathrm{~m} \times 12 \mathrm{~m}$ & 32.11 & 36.23 & $12.1 \%$ \\
\hline $60 \mathrm{~m} \times 12 \mathrm{~m}$ & 2.39 & 2.66 & $10.7 \%$ \\
\hline
\end{tabular}

Table 1. Values of the obtained safety factor estimates for different geometries

from an engineering point of view. One interesting aspect of the yield design, in particular the kinematic approach, is that an optimal collapse mechanism is obtained and can provide valuable information for the designer. For example, the collapse mechanism represented in Figure 7 shows that most of the collapse takes place in the bottom part of the wall, the out-of-plane collapse velocity reaching its maximum at approximately $3 \mathrm{~m}$ from the ground. This is confirmed by the contour plot of the support function of Figure 8 which shows that the highest resisting work ("dissipation") takes place in the bottom corners and in a central region near the bottom of the wall.

The above described three-step procedure has been then applied to a high rise wall having exactly the same geometrical, loading and strength characteristics as the previous one, except that the width was equal to $60 \mathrm{~m}$ instead of $12 \mathrm{~m}$. This example may not seem very realistic but serves as a limit case example to better illustrate the influence of the lateral boundary conditions on the collapse mechanism and the safety factor. Figure 9 shows the contours of the out-of-plane displacements produced by the same thermal gradient. It is worth noting that the maximum value is almost equal to $90 \mathrm{~cm}$, that is three times the corresponding value of the square panel (Figure 4).

The associated lower and upper bound estimates for the stability factor, which remain relatively close to each other (relative difference of 11\%), are reported in the bottom line of Table 1 . They show a considerable reduction of the stability factor estimates, which are decreased by a factor almost equal to 14 . Figure 10 displays the failure mechanism resulting from the finite element optimization of the upper bound kinematic approach, where it could be observed that it involves an in-plane horizontal velocity jump along the vertical central line. The corresponding distribution of the support function (dissipation or maximum resisting work per unit area) is displayed in Figure 11. Note that the contribution of the different velocity jump lines between adjacent elements, and notably the above mentioned central vertical velocity jump line, is not accounted for in the latter figure.

\section{CONCLUDING REMARKS}

It has been shown in this paper, that the combination of a yield design homogenization method for periodic plates, with a fem-based numerical approach, involving non-linear optimization schemes implemented through dedicated solvers, makes it possible to assess the stability of a high rise reinforced

concrete panel under fire loading in a rather quick way, leading to fairly accurate bounds on the panel overall stability factor. The computational procedure can be easily generalized to other situations where the geometrical, material, as well as thermal loading characteristics can be varied, allowing for parametric studies.

One of the most important input data necessary to perform such a stability analysis, is to obtain a reliable evaluation of the wall deformed configuration due to thermal loading. Indeed, as it has been proved on the illustrative example investigated in this paper, the amplitude of the out-of-plane displacements has a considerable influence on the wall stability, which is highly sensitive to the lateral boundary conditions.

In this respect, the current evaluation method, based on a second order thermo-elastic analysis, probably provides a conservative estimate for the wall deflection, since only material stiffness, and not yield, properties are accounted for in the analysis. This point certainly requires further investigations in the near future, without it being necessary to resort to sophisticated and complex incremental computational methods, hardly compatible with an engineering design approach.

\section{REFERENCES}

Averbuch D (1996) A yield design approach to reinforced concrete structures. PhD thesis, ENPC, Paris, France; [in French].

Bazant, Z \& Cedolin, L (2010) Stability of Structures: Elastic, Inelastic, Fracture and Damage Theories. World Scientific, Singapore.

Bleyer, J \& de Buhan, P (2013) On the performance of non-conforming finite elements for the upper bound limit analysis of plates. International Journal for Numerical Methods in Engineering; 94(3): 308-330.

Bleyer, J \& de Buhan, P (2014) A computational homogenization approach for the yield design of periodic thin plates-Part I: Construction of the macroscopic strength criterion. International Journal of Solids and Structures; 51: 2448-2459.

Caldas, RB \& Sousa Jr, JBM \& Fakury, R.H. (2010) Interaction diagrams for reinforced concrete sections subjected to fire. Engineering Structures; 32(9):2832-2838.

Chen, WF (1982) Plasticity in reinforced concrete. McGraw-Hill, New-York, USA.

El-Fitiany, SF \& Youssef, MA (2009) Assessing the flexural and axial behaviour of reinforced concrete members at elevated temperatures using sectional analysis. Fire Safety Journal; 44(5):691-703.

EN1991-1-2 (2002) Eurocode 1: Action on structures-Part 1-2: General actions-Actions on structures exposed to fire.

EN1992-1-2 (2004) Eurocode 2: Design of concrete structures-Part 12: General rules-Structural fire design.

Franssen, JM \& Dotreppe, JC (2003) Fire tests and calculation methods for circular concrete columns. Fire Technology; 39(1):89-97.

Koechlin, P \& Potapov, S (2007) Global constitutive model for reinforced concrete plates. Journal of Engineering Mechanics, ASCE; 133(3):257-266. 


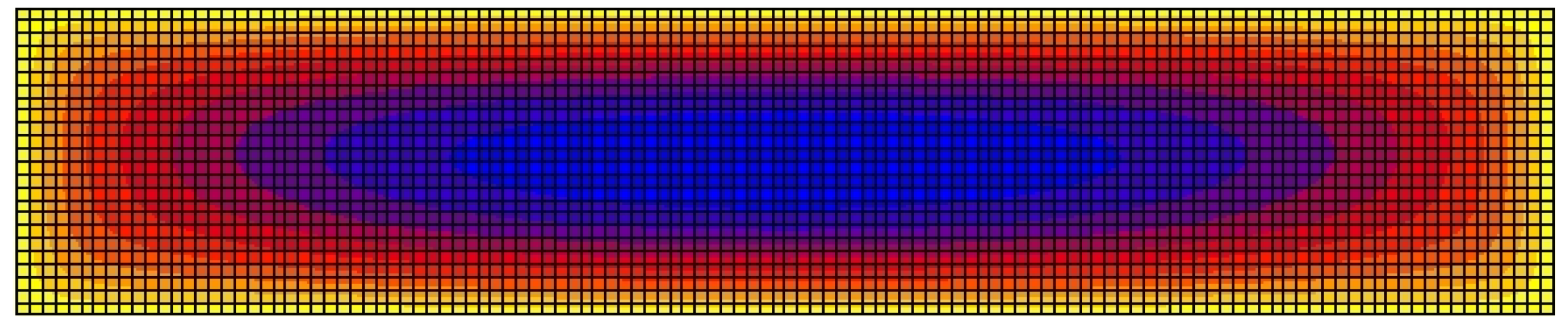

\begin{tabular}{|c|c|c|c|c|c|c|c|c|c|c|}
\hline $\begin{array}{l}\infty \\
0 \\
0 \\
0 \\
0 \\
0 \\
0\end{array}$ & $\begin{array}{c}\mathrm{d} \\
\mathrm{g} \\
1 \\
0 \\
0 \\
0 \\
0\end{array}$ & 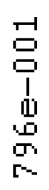 & 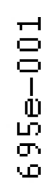 & 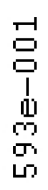 & 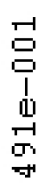 & 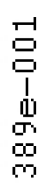 & 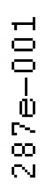 & 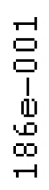 & 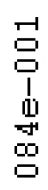 & 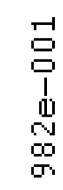 \\
\hline$\nabla$ & 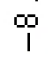 & $\vec{r}$ & $\mathrm{i}$ & 9 & $\vec{j}$ & 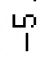 & 19ים & $\widetilde{1}$ & $\stackrel{1}{1}$ & $\stackrel{9}{1}$ \\
\hline
\end{tabular}

Fig. 9. Contours of the panel out-of-plane displacements for $L=60 \mathrm{~m}$ : face view.

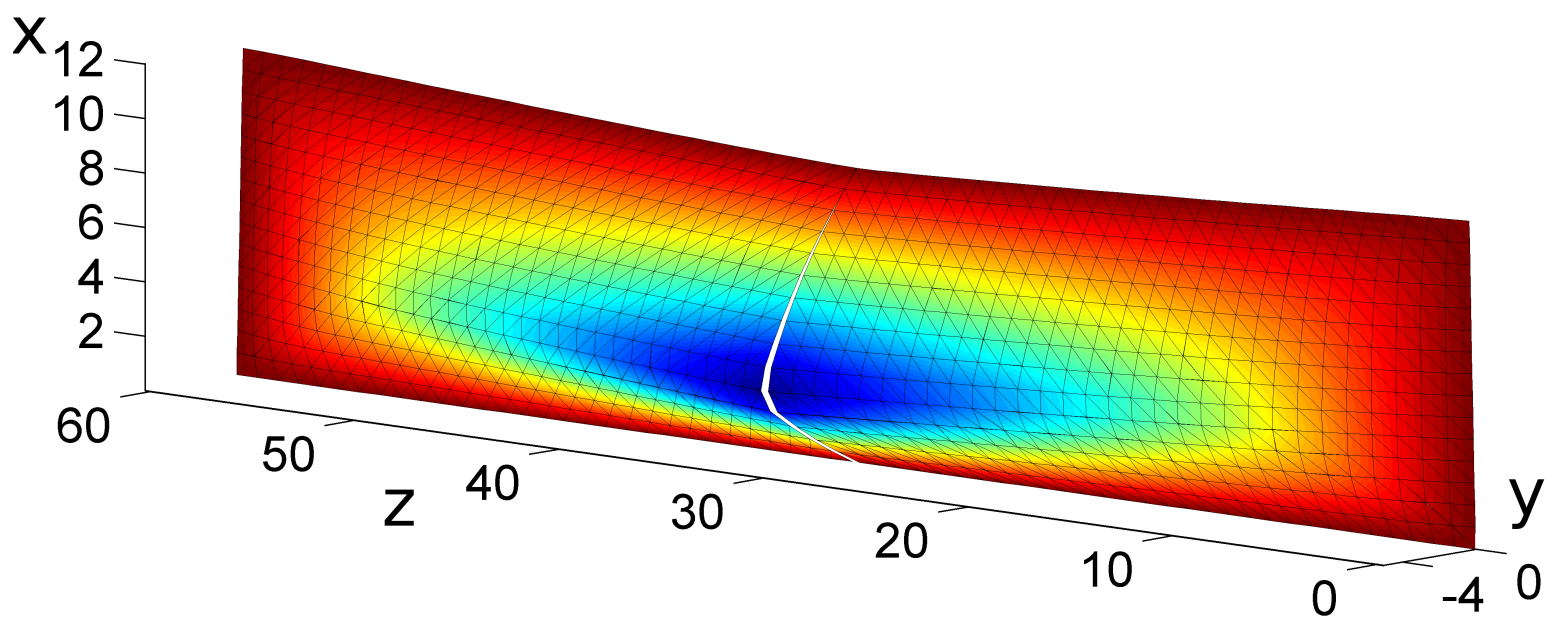

Fig. 10. Optimal failure mechanism obtained in the kinematic approach for $L=60 \mathrm{~m}$ (contours represent the relative amplitude of the $U_{y}$ velocity)

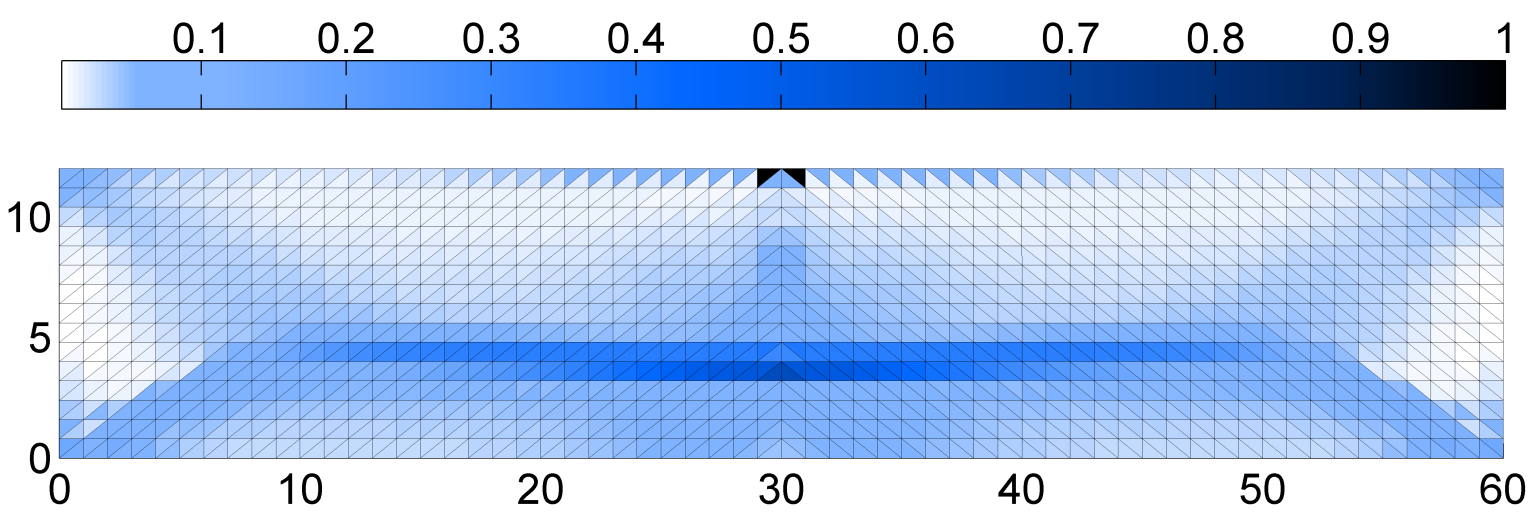

Fig. 11. Relative distribution of the support function $\pi^{h o m}(\underline{\underline{\delta}}, \underline{\underline{\chi}})$ for $L=60 \mathrm{~m}$ : face view

Law, A \& Gillie, M (2010) Interaction diagrams for ambient and heated concrete sections. Engineering Structures; 32(6):1641-1649.

Lie, TT \& Celikkol, B (1991) Method to calculate the fire resistance of circular reinforced concrete columns. ACI Materials Journal; 88(1):84-91
MOSEK ApS (2002) C/O Symbion Science Park, Copenhagen, Denmark, www.mosek.com

MSC. Software Corporation (2007) User documentation of MSC Marc. Pham, DT \& de Buhan, P \& Florence, C \& Heck, JV \& Nguyen, HH (2015a) Interaction diagrams of reinforced concrete sections in fire: 
a yield design approach. Engineering Structures, 90, 38-47.

Pham, DT \& de Buhan, P \& Florence, C \& Heck, JV \& Nguyen, HH

(2015b) Yield design-based analysis of high rise concrete walls subjected to fire loading conditions. Engineering Structures, 87, 153-161.

Salençon, J (2013) Yield design. ISTEWiley, Hoboken, NJ USA. 